\title{
EFFECT OF SKEW ANGLE ON STATIC BEHAVIOUR OF REINFORCED CONCRETE SLAB BRIDGE DECKS
}

\author{
Sindhu B.V ${ }^{1}$, Ashwin K.N ${ }^{2}$, Dattatreya J.K. ${ }^{3}$, S.V Dinesh ${ }^{4}$ \\ ${ }^{1}$ Post Graduate Student, ${ }^{2}$ Assistant Professor, ${ }^{3}$ Research Professor, ${ }^{4}$ Professor and Head, Department of Civil \\ Engineering, Siddaganga Institute of Technology, Tumkur \\ sindhubvr@gmail.coml,meetashwinkn@yahoo.com,jk.dattatreya@gmail.com,dineshsv2004@yahoo.com
}

\begin{abstract}
The effect of a skew angle on single-span reinforced concrete bridges is analyzed using the finite-element method and the results are presented in this paper. Investigations are carried out on RC slab bridge decks with and without edge beams to study the influence of aspect ratio, skew angle and type of load. The finite-element analysis results for skewed bridges are compared to the reference straight bridges for dead load, IRC Class A loading and IRC 70R loading for with and without edge beam. A total of 90 bridge models are analyzed. The variation of maximum deflection, maximum longitudinal sagging bending moment, maximum torsional moment, and maximum support reaction with skew angle is studied for all 90 bridge deck models. The FEA results of Dead load and Live load bending moments and deflections decreases with increase in skew angle, where as maximum support reactions increases with increase in skew angle and the maximum torsional moment increases with skew angle up to 45 degrees and there after decreases. The benefit of providing edge beam is reflected in significant decrease in deflection, longitudinal bending moment and torsional moment.
\end{abstract}

Keywords: Bridges, skew angle; Concrete slabs; Finite element method; span length; dead load; IRC Class A loading and IRC Class 70R loading.

\section{INTRODUCTION}

Skewed bridges are often encountered in highway design when the geometry cannot accommodate straight bridges. The skew angle can be defined as the angle between the normal to the centreline of the bridge and the centreline of the abutment or pier cap, as described in Fig. 2. Skew bridges have become a necessity due to site considerations such as alignment constraints, land acquisition problems, etc. The presence of skew in a bridge makes the analysis and design of bridge decks intricate. For the Slab bridge decks with small skew angle, it is considered safe to analyze the bridge as a right bridge with a span equal to the skew span.

In non skewed bridges, the load path is straight toward the support (Fig 1a). In skewed bridges, the load tends to take a shortest path to the nearest support i.e. to the obtuse corners of the bridge here the maximum deflection occurs at obtuse angled corner (Fig 1b).

Khaleel et al., (1990) presented a method for determining moments in continuous normal and skew slab-and-girder bridges due to live loads. Menassa et al. (2007) compared the effect o skew angle with reference to straight bridge and reported that the bridges with skew angle less than 20 degree can be designed as non skew as the moments are almost same for both. Vikash Khatri et al. (2012) compared grillage method and finite element method of analysis and recommended the use of FEM because of closes agreement with the exact solution. Patrick Theoret et al., (2012) studied the bending moments and shear forces, required to design skewed concrete slab bridges.

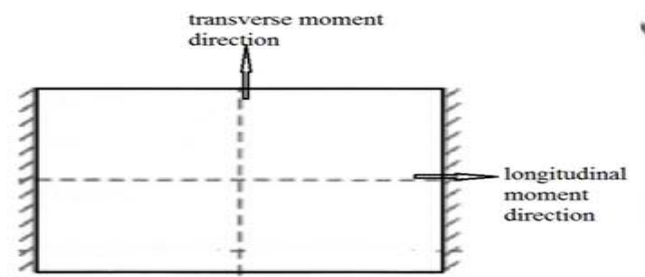

(a)

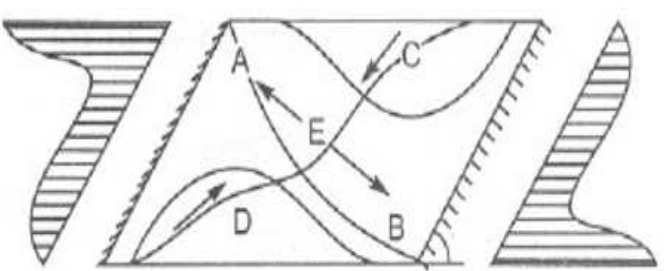

(b)

Fig1. Direction of moment flow in straight and skewed bridge decks 


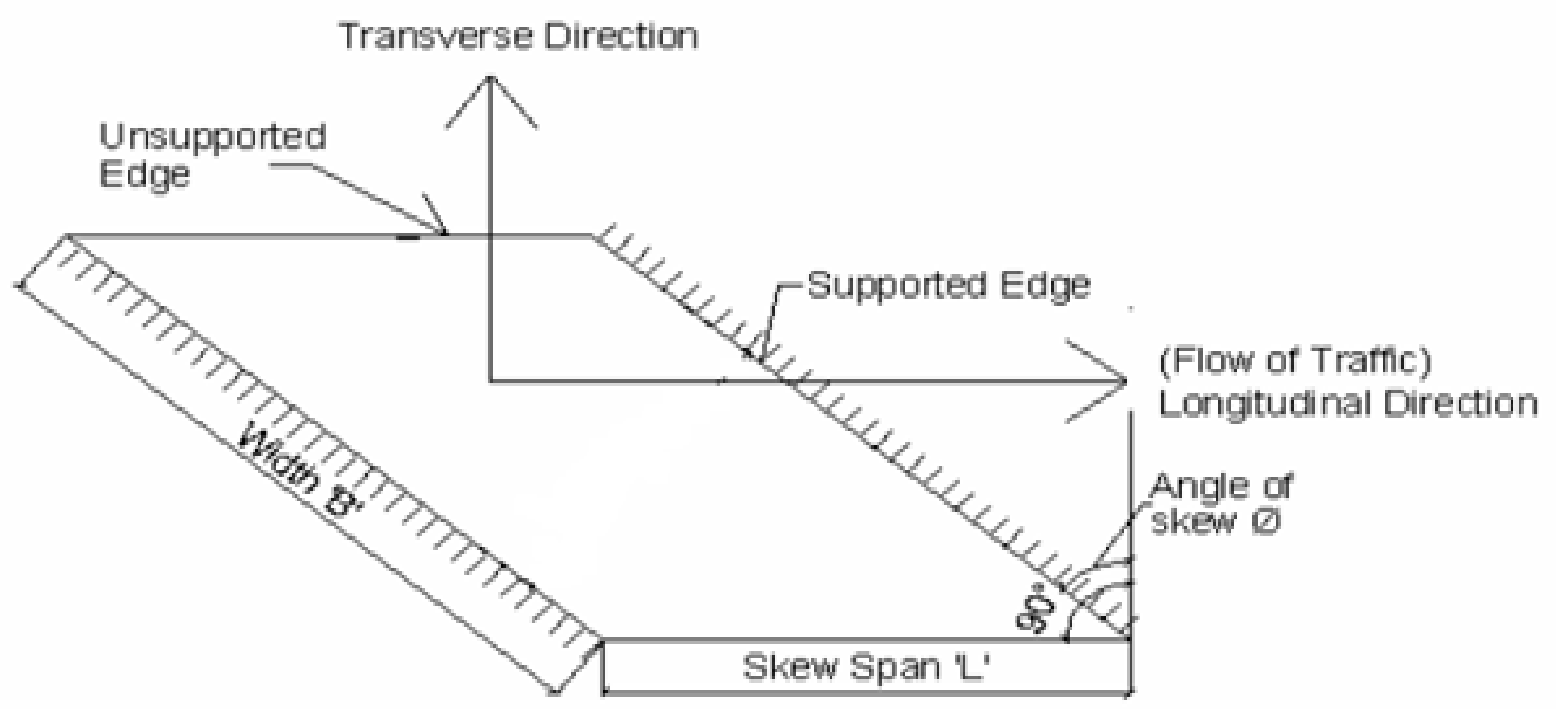

Fig2: Skew Bridge

\section{PARAMETRIC STUDY}

A simply supported, single span, two lane RC slab bridge deck is considered. The span is varied from 5, 7.5 and 9.5m (aspect ratio 1) and skew angle is varied from $0^{\circ}$ to $60^{\circ}$ at $15^{\circ}$ interval is considered with the depth of the slab $750 \mathrm{~mm}$ for all spans. Edge beam of depth $1.5 \mathrm{~m}$ and width of $0.3 \mathrm{~m}$ is provided. The bridge deck is analyzed for Dead load as well as two classes of live load i.e. IRC Class A and IRC Class 70R. Comparison of critical structural response parameter of above cases is presented in the following for slabs with and without edge beam. A total of 90 slab deck models have been analyzed

Table 1: Geometric parameters slab bridge decks

\begin{tabular}{|l|l|l|l|}
\hline No & Span(m) & Width(m) & $\begin{array}{l}\text { Aspect ratio } \\
\text { (span/width) }\end{array}$ \\
\hline 1 & 5 & 9.5 & 0.526 \\
\hline 2 & 7.5 & 9.5 & 0.789 \\
\hline 3 & 9.5 & 9.5 & 1 \\
\hline
\end{tabular}

\section{LOAD ON BRIDGE DECK MODELS}

The vehicular live load consist of a set wheel loads and are treated as concentrated loads acting at centres of contact areas, two classes of load i.e. IRC Class A and IRC 70R are considered for analysis. The peak values of critical structural response parameter such as deflection, longitudinal sagging bending moment, torsional moment and support reaction are analyzed. Different positions of each type of loading systems are considered from table 2 of IRC 6:2000.

\section{FINITE ELEMENT MODELING}

The analysis is carried out using finite element method. The concrete slabs are modelled using four noded plate elements and edge beams using two noded beam elements. Simple support condition is provided.

\begin{tabular}{|l|l|}
\hline ELASTIC MODULUS & $25000 \mathrm{Mpa}$ \\
\hline POISSON'S RATIO & 0.2 \\
\hline DENSITY OF CONCRETE & $25 \mathrm{kN} / \mathrm{m} 2$ \\
\hline
\end{tabular}

\section{RESULTS AND DISCUSSION}

The FEA results are obtained and presented in terms of critical structural response parameter such a deflection, longitudinal sagging bending moment, torsional moment, and support reaction in the bridge deck models due to the applied wheel load. The variations of the critical structural response parameter due to changes in skew angle are presented in the following.

\subsection{Deflection}

- It is observed that the maximum deflection for skewed slab deck for all types of load compared to that of straight deck slab decreases with the increase in skew angle for all aspect ratios as 
shown in figure 3 . This is because the maximum force flow between the support lines is through the strip area connecting the obtuse angled corners, as skew increases the length of strip area decreases. Hence the bending moment and deflection also registers significant reduction.

- When the deflection for different skew angle and aspect ratios are normalised with respect to the deflection corresponding to zero skew of that particular aspect ratio. The different curves as seen in fig 3(a) nearly merge into a single curve as shown in fig 6(a).
- The normalized deflection i.e. D $\alpha / \mathrm{D} 0$ for slab decks without edge beams for all aspect ratios reduces from unit value to 0.26 for dead load and for IRC Class A load, unit value to 0.64 for IRC Class 70R load.

- The deflection of deck slab decreases with the provision of edge beam compared to the slab decks without edge beam. There is nearly $10 \%$ reduction in deflection due to the provision of edge beam in the slab bridge deck.

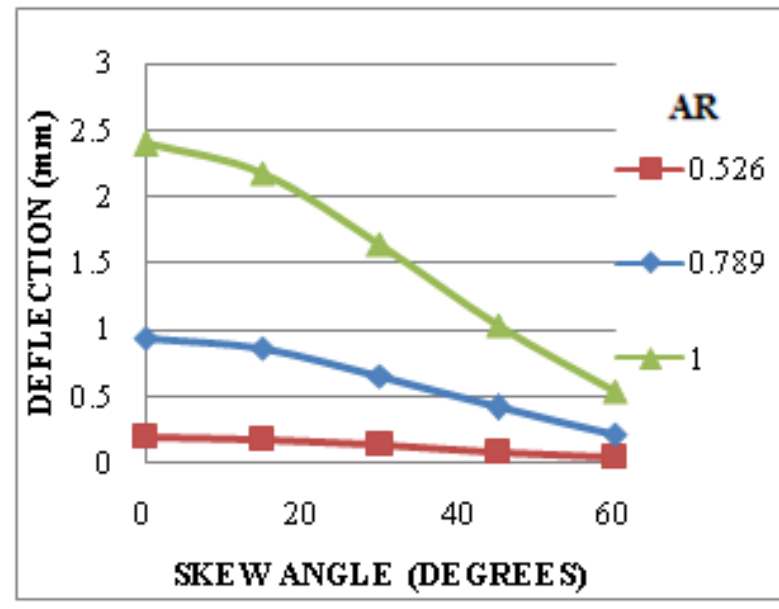

a) Dead Load (Without Edge Beam)

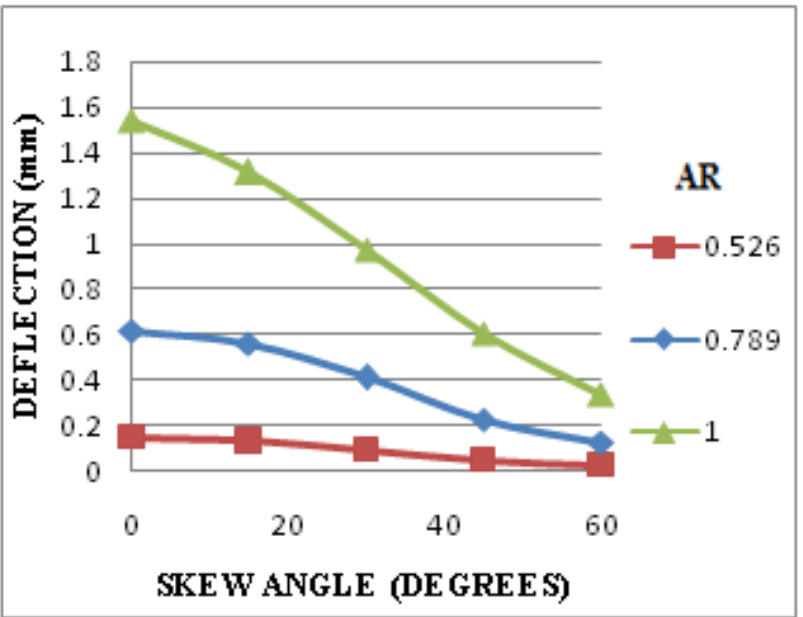

b) Dead Load (With Edge Beam)

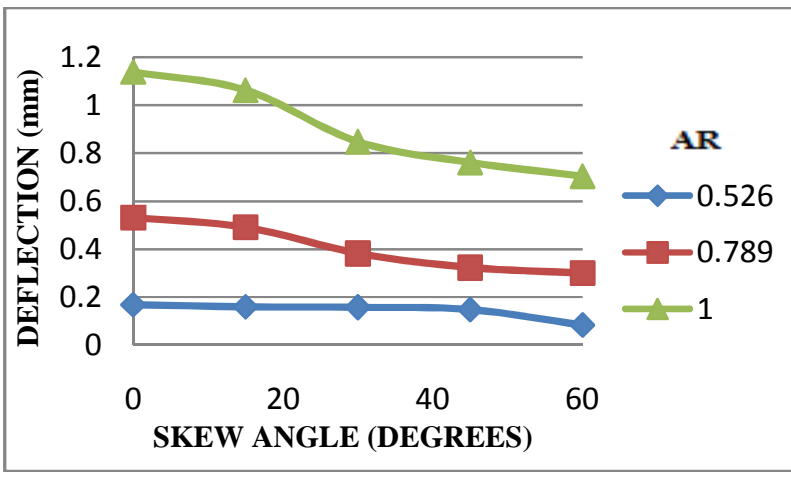

c) IRC Class A Load (Without Edge Beam)

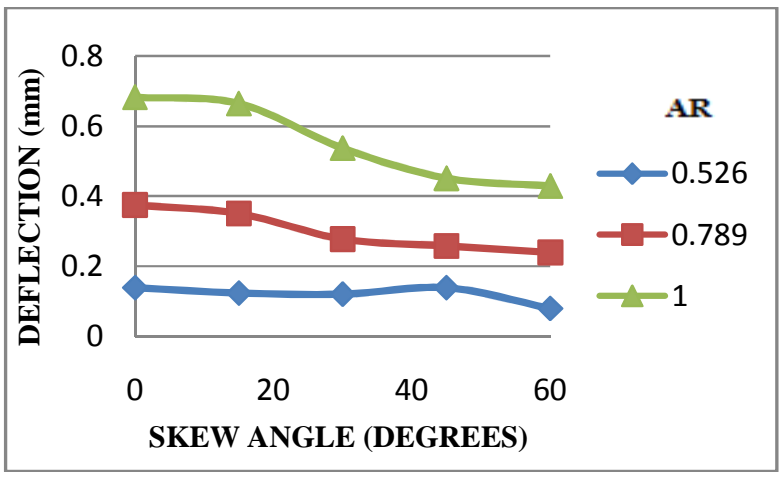

d) IRC Class A Load (With Edge Beam) 


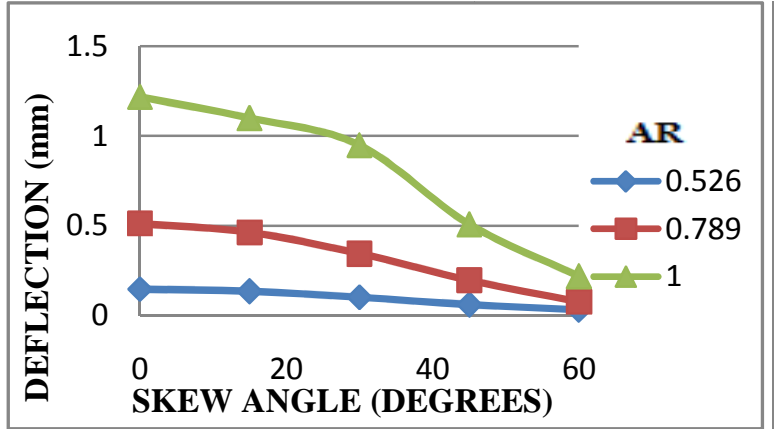

e) IRC Class70R Load (Without Edge Beam)

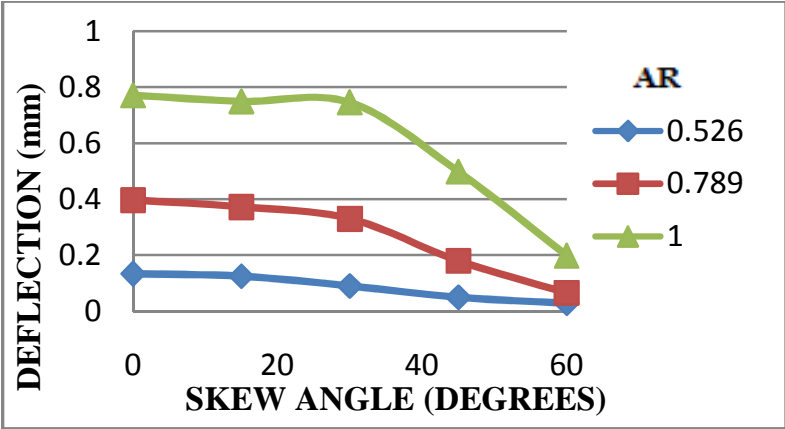

f) IRC Class 70R Load (With Edge Beam)

Fig 3 Variation of Deflection Due To Dead Load and Live Load on Deck Slab without and With Edge Beams

\subsection{Longitudinal Bending Moment}

- The trend in longitudinal bending moment is similar to deflection. It is observed that the maximum dead load longitudinal bending moment and wheel load longitudinal bending moment for skewed deck slabs compared to that of straight deck slab decreases with the increase in skew angle for all aspect ratios as shown in fig 4 . This is because the force flow between the support lines is through the strip area connecting the obtuse angled corners, as skew increases the length of strip area decreases therefore the moment decreases.

- When the longitudinal bending moment for different skew angle and aspect ratios are normalised with respect to the longitudinal bending moment corresponding to zero skew of that particular aspect ratio. The different curves as seen in fig 4(a) nearly merge into a single curve as shown in fig 6(b).

- The normalized longitudinal bending moment i.e. $\mathrm{M} \alpha / \mathrm{M} 0$ varies from unity to 0.33 for deck slabs without edge beam for dead load, unity to 0.74 for IRC Class A load and unity to 0.79 for IRC Class 70R load for all aspect ratios.

- The longitudinal bending moment decreases with the provision of edge beam for both dead load and wheel load compared to without edge beam. There is almost $10 \%$ reduction in longitudinal bending moment due to the provision of edge beam in the slab bridge deck.

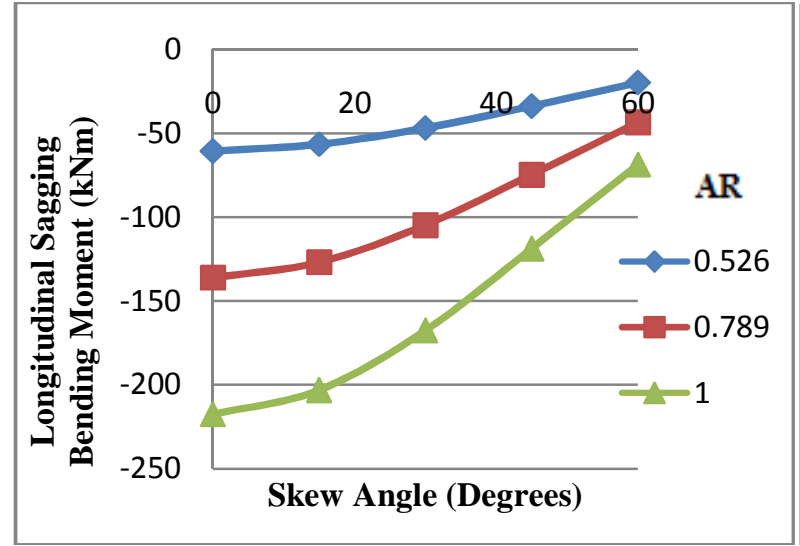

a) Dead Load (Without Edge Beam)

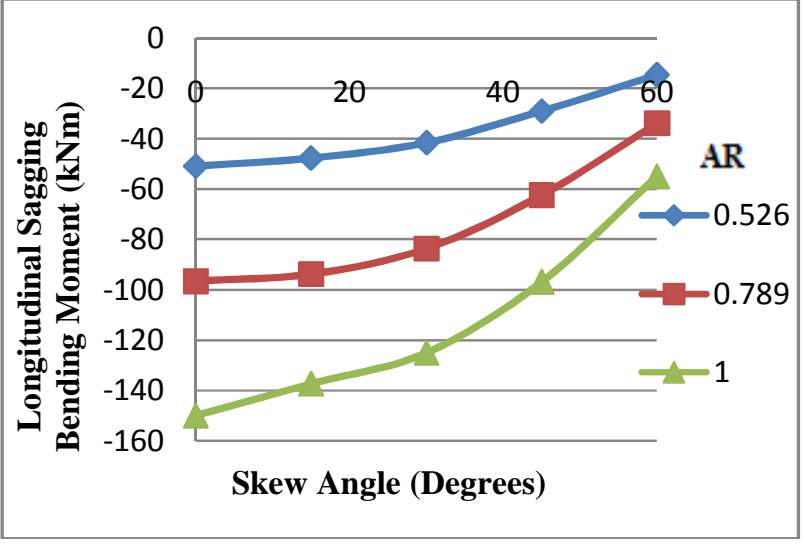

b) Dead Load (With Edge Beam) 


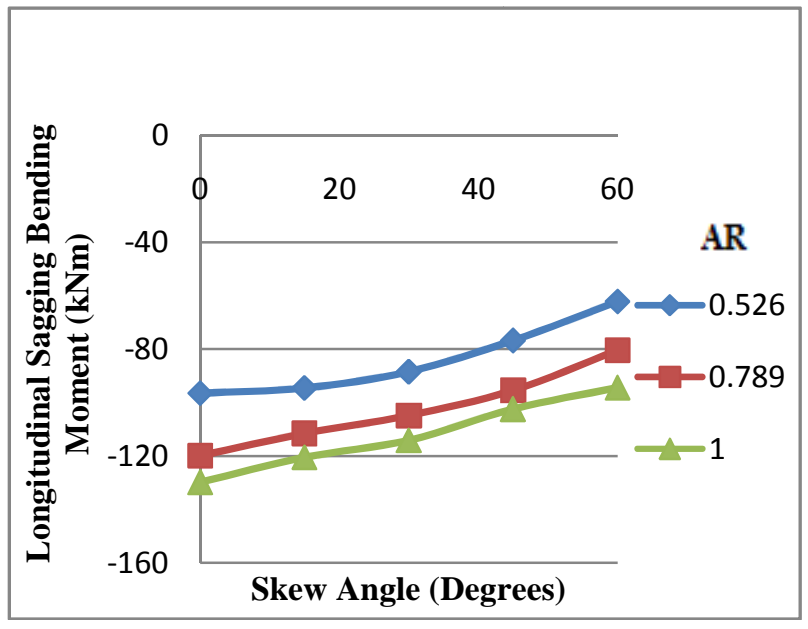

c) IRC Class A Load (Without Edge Beam)

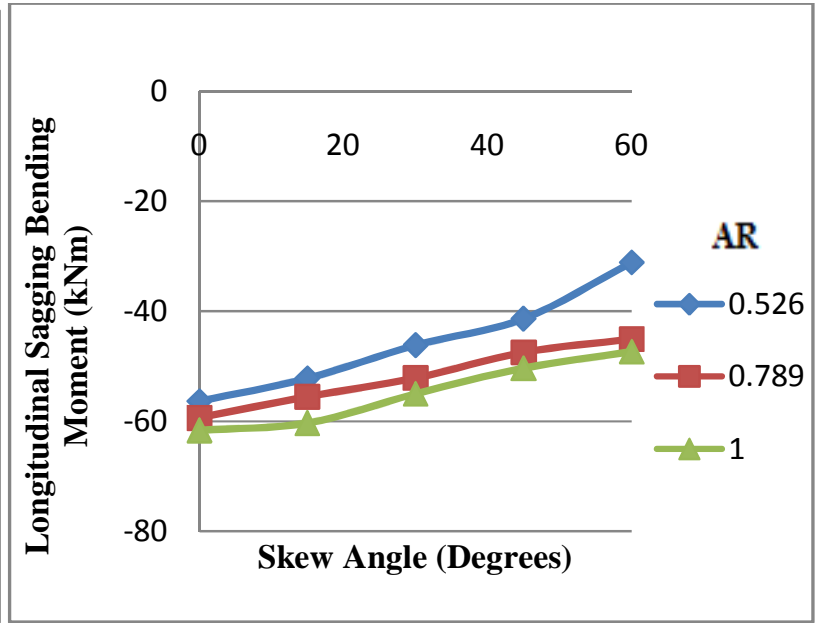

d) IRC Class A Load (With Edge Beam)

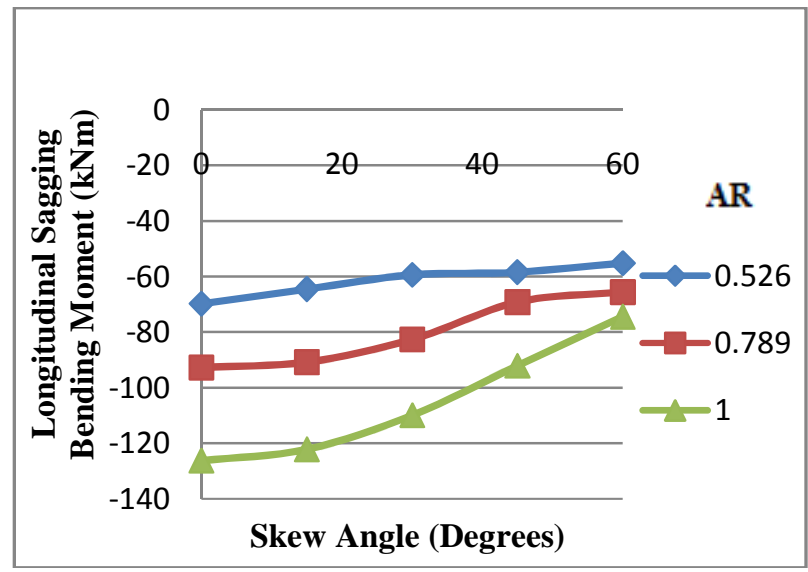

e) IRC Class70R Load (Without Edge Beam)

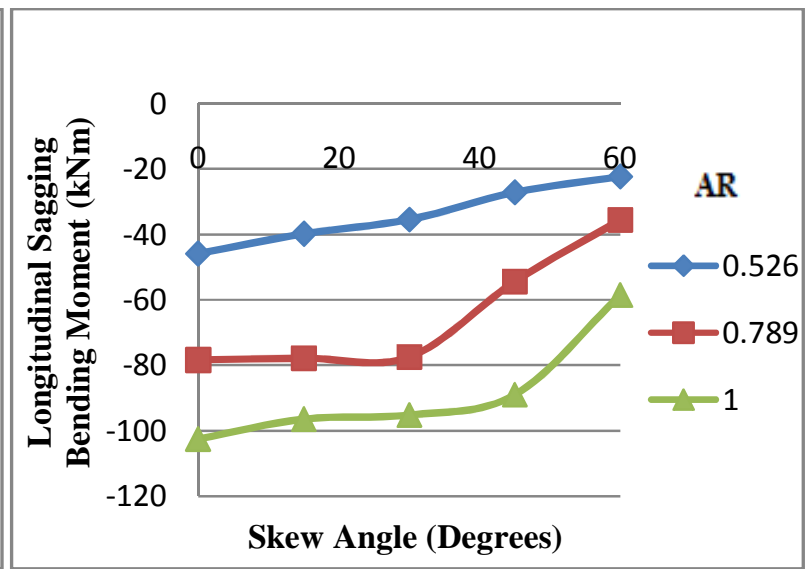

f) IRC Class 70R Load (With Edge Beam)

Fig 4 Variation of Longitudinal Bending Moment Due To Dead Load and Live Load on Deck Slab Without and With Edge Beams

\subsection{Torsional Moment}

- The dead load and wheel load torsional moments for skewed deck slab increases with the increase in skew angle for all aspect ratios up to 45 degrees and then decreases for further increase in skew angle.

- The Torsional moment for different skew angle and aspect ratios are normalised with respect to the Torsional moment corresponding to zero skew of that particular aspect ratio. The different curves as seen in fig 5(a) nearly merge into a single curve as shown in fig 6(c).
- The normalized Torsional moment i.e. TM $\alpha / \mathrm{TMo}$ increases from unity to 3.33 up to $30^{\circ}$ and decreases from 2.36 to 1.84 for $45^{\circ}$ to $60^{\circ}$ for deck slabs without edge beam for dead load, unity to 3.5 up to $45^{\circ}$ and 3.2 for $60^{\circ}$ for IRC Class A load and unity to 1.5 up to $45^{\circ}$ and 0.9 for $60^{\circ}$ for IRC Class $70 \mathrm{R}$ load for all aspect ratios.

- The torsional moment decreases with the provision of edge beam for both dead load and wheel load compared to without edge beam. There is almost $50 \%$ reduction in Torsional moment due to the provision of edge beam in the slab bridge deck. 


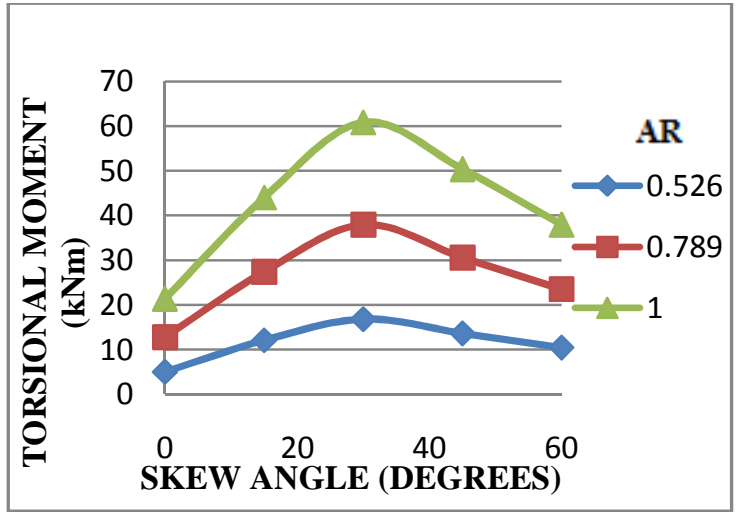

a) Dead Load (Without Edge Beam)

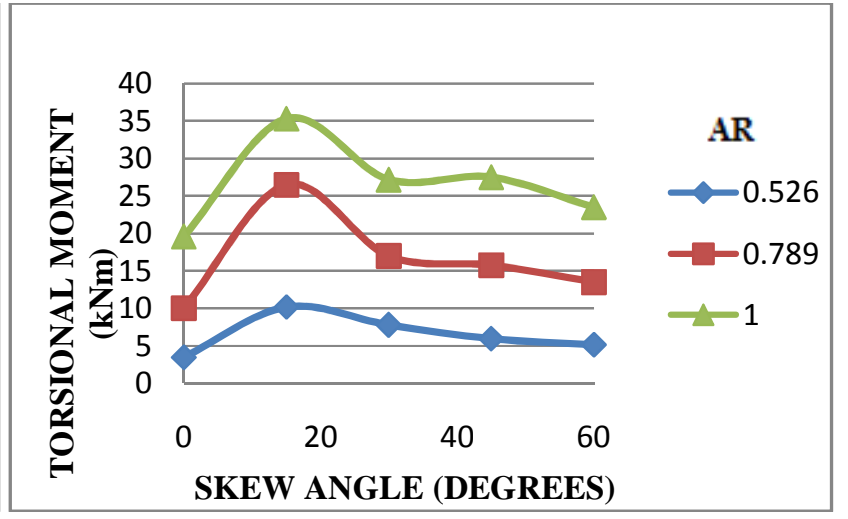

b) Dead Load (With Edge Beam)

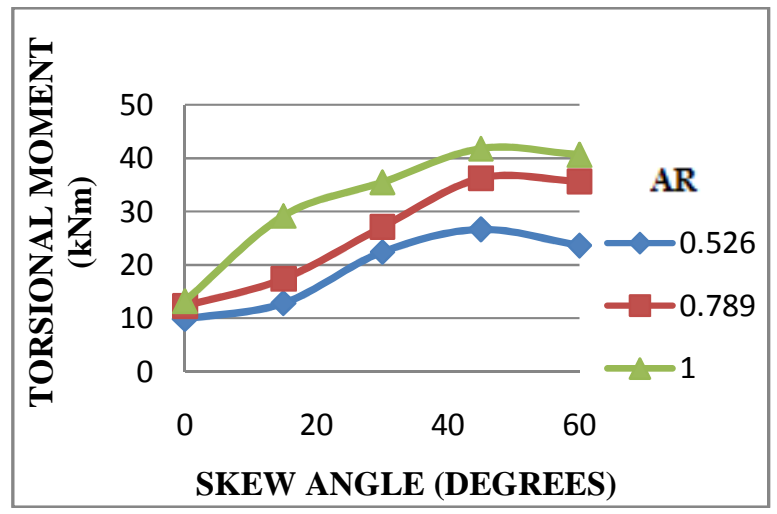

c) IRC Class A Load (Without Edge Beam)

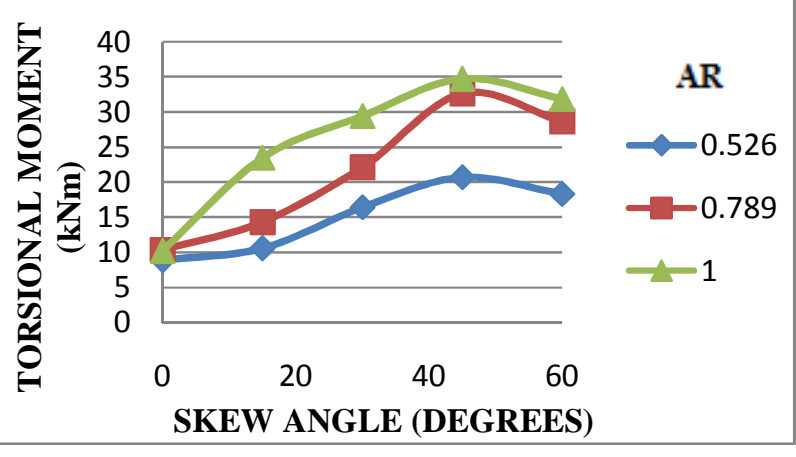

d) IRC Class A Load (With Edge Beam)

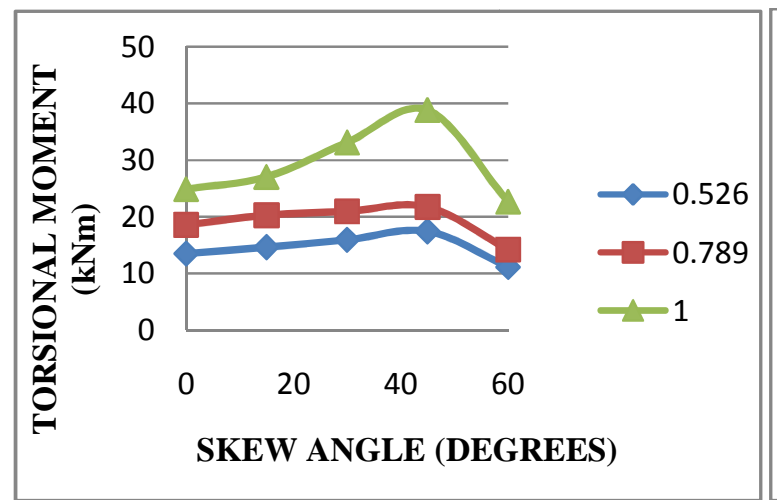

e) IRC Class70R Load (Without Edge Beam)

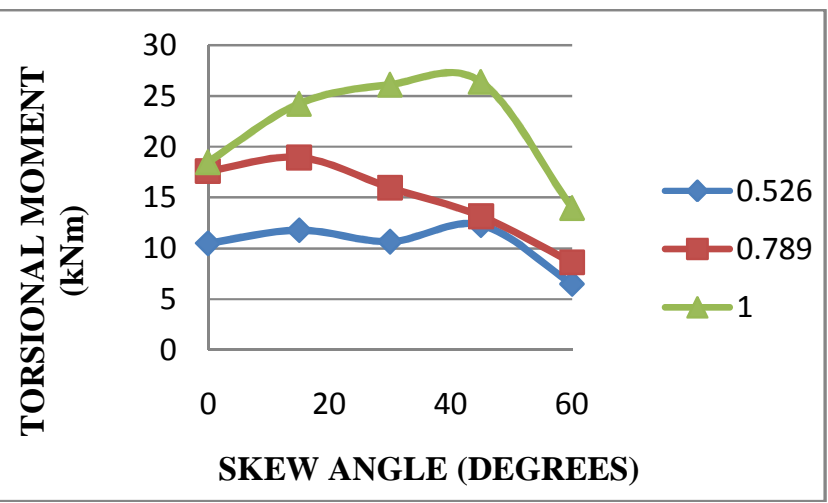

f) IRC Class 70R Load (With Edge Beam)

Fig 5 Variation of Torsional Moment of Deck Slab with Skew Angle

\subsection{Support Reaction at Obtuse Angled Corner.}

- The maximum dead load and wheel load support reactions at the obtuse angled corner of deck slab increases with increase in skew angle as shown in table 2, 3 and 4 . The reactions at the obtuse angled end of slab support are larger than other end, the increase in value over average value ranging from 0 to $50 \%$ for skew angle of 15 to $45^{\circ}$. It increases around $80 \%$, when it reaches $60^{\circ}$ compared to right bridge. 
- The normalized Support reaction i.e. S $\alpha / \mathrm{S} 0$ varies from unity to 7 for deck slabs without edge beam for dead load, unity to 8 for IRC Class A load and unity to 10 for IRC Class 70R load for all aspect ratios.
- $\quad$ The support reaction increases when edge stiffening beam is provided with comparison of the deck slabs without edge beams. There is almost $10 \%$ increase in support reactions due to the provision of edge beam in the slab bridge deck.

Table 2: Dead Load Support reaction

\begin{tabular}{|c|c|c|c|c|c|c|}
\hline & \multicolumn{6}{|c|}{ Maximum Support Reaction(kN) } \\
\hline & \multicolumn{6}{|l|}{ Aspect Ratio } \\
\hline & \multicolumn{2}{|l|}{0.526} & \multicolumn{2}{|l|}{0.789} & \multicolumn{2}{|l|}{1} \\
\hline Skew Angle & $\begin{array}{l}\text { Without Edge } \\
\text { Beam }\end{array}$ & $\begin{array}{l}\text { With Edge } \\
\text { Beam }\end{array}$ & $\begin{array}{l}\text { Without } \text { Edge } \\
\text { Beam }\end{array}$ & $\begin{array}{l}\text { With Edge } \\
\text { Beam }\end{array}$ & $\begin{array}{l}\text { Without Edge } \\
\text { Beam }\end{array}$ & $\begin{array}{ll}\text { With } & \text { Edge } \\
\text { Beam } & \end{array}$ \\
\hline 0 & 7.913 & 20.916 & 14.676 & 43.524 & 21.198 & 97.274 \\
\hline 15 & 13.202 & 31.551 & 27.077 & 60.061 & 42.296 & 96.171 \\
\hline 30 & 21.853 & 35.823 & 51.272 & 79.662 & 84.355 & 130.331 \\
\hline 45 & 30.903 & 40.58 & 75.019 & 93.637 & 126.489 & 156.137 \\
\hline 60 & 35.348 & 37.835 & 84.406 & 89.735 & 144.521 & 152.775 \\
\hline
\end{tabular}

Table 3: IRC Class A Loading Support reaction

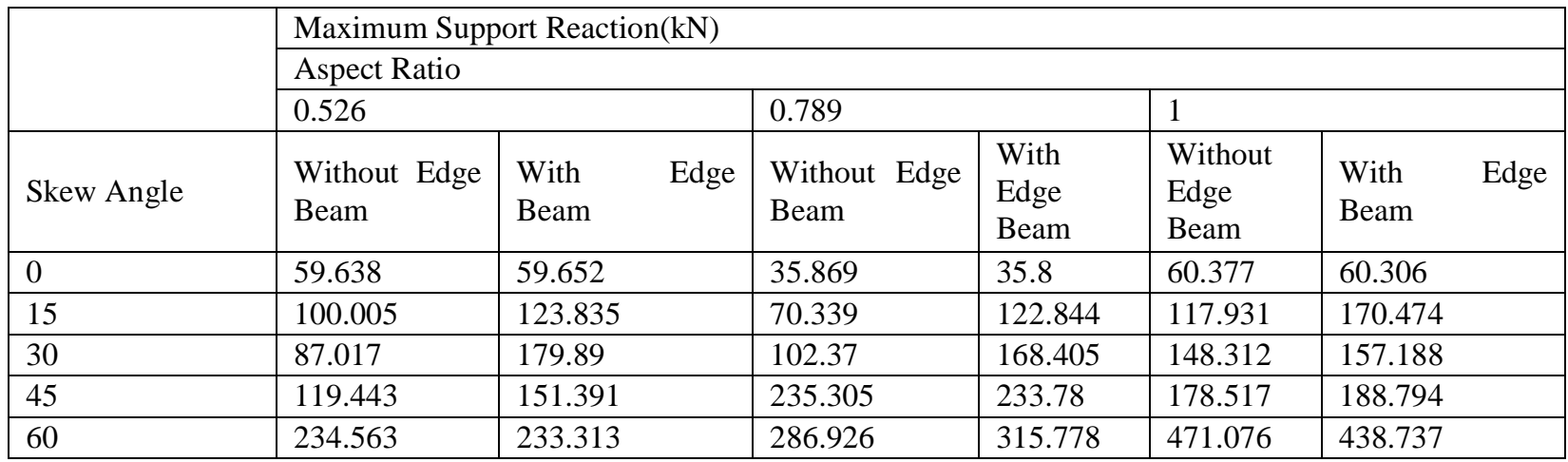

Table 4: IRC Class 70R Loading Support reaction

\begin{tabular}{|c|c|c|c|c|c|c|c|c|c|}
\hline \multirow{4}{*}{ Skew Angle } & \multicolumn{9}{|c|}{ Maximum Support Reaction(kN) } \\
\hline & \multicolumn{9}{|c|}{ Aspect Ratio } \\
\hline & \multicolumn{3}{|l|}{0.526} & \multicolumn{3}{|l|}{0.789} & \multicolumn{3}{|l|}{1} \\
\hline & $\begin{array}{l}\text { Without Edge } \\
\text { Beam }\end{array}$ & $\begin{array}{l}\text { With } \\
\text { Beam }\end{array}$ & Edge & $\begin{array}{l}\text { Without } \\
\text { Beam }\end{array}$ & Edge & $\begin{array}{l}\text { With } \\
\text { Edge } \\
\text { Beam }\end{array}$ & $\begin{array}{l}\text { Without } \\
\text { Edge } \\
\text { Beam }\end{array}$ & $\begin{array}{l}\text { With } \\
\text { Beam }\end{array}$ & Edge \\
\hline 0 & 44.863 & 44.851 & & 43.767 & & 43.679 & 42.5 & 42.5 & \\
\hline 15 & 163.38 & 163.411 & & 195.326 & & 186.26 & 176.343 & 175.653 & \\
\hline 30 & 170.261 & 170.273 & & 168.77 & & 169.017 & 169.293 & 169.561 & \\
\hline 45 & 166.008 & 235.094 & & 157.151 & & 202.951 & 161.976 & 185.883 & \\
\hline 60 & 164.924 & 289.43 & & 164.799 & & 406.386 & 172.906 & 418.8 & \\
\hline
\end{tabular}




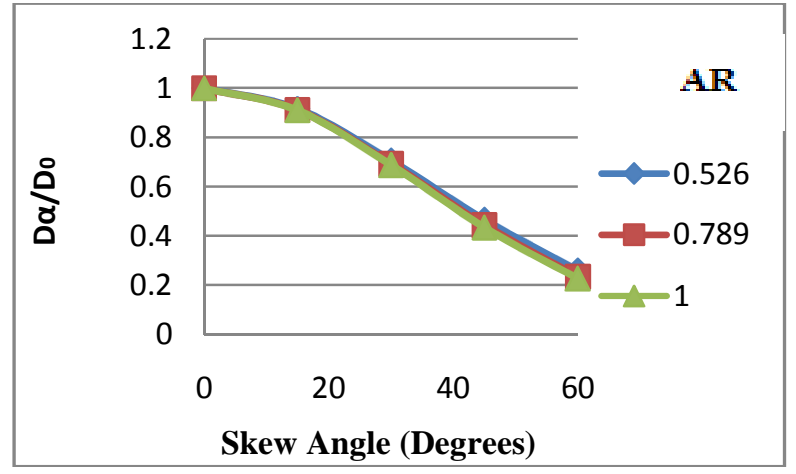

(a)

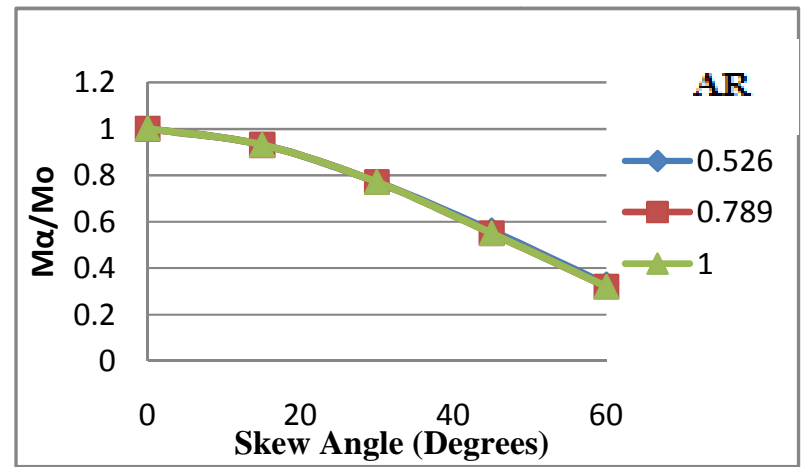

(b)

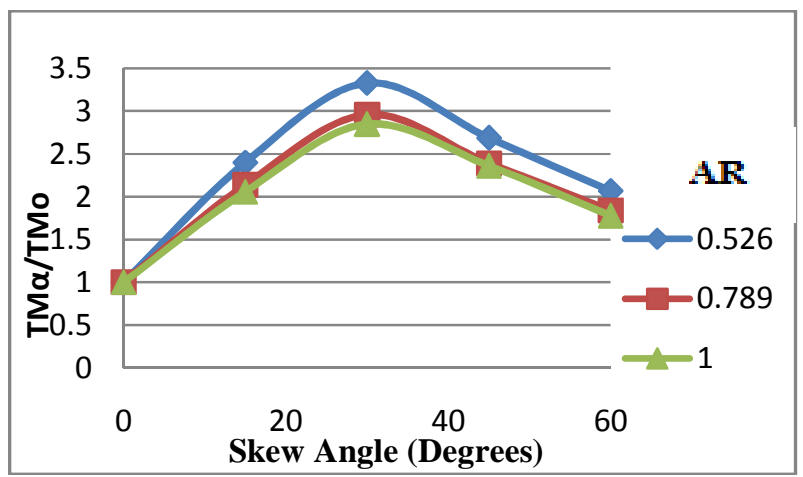

(c)

Fig 6 Variation of Normalised values of deflection, longitudinal moment and Torsional Moment of Deck Slab with Skew Angle

\section{CONCLUSIONS}

1) The maximum deflection for skewed deck slabs decreases with the increase in skew angle for all aspect ratios and at $60^{\circ}$ the reduction is around $75 \%$ in Slab Bridge without edge beam and about $90 \%$ reduction is seen for slabs with edge beam when compared to right bridge without edge beam for all aspect ratio for dead load. A similar trend is observed in case of wheel load but the order of reduction is comparatively less i.e. about $40 \%$ to $50 \%$ compared to the case of dead load.

2) Longitudinal bending moment shows similar pattern of reduction with increase in skew angle and maximum reduction due to dead load is found to be $70 \%$ for a skew angle $60^{\circ}$ compared to right bridge without edge beam for all aspect ratio; When edge beam is provided it decreases around $75 \%$ for a skew angle $60^{\circ}$ compared to right bridge without edge beam for all aspect ratio. Maximum wheel load longitudinal bending moment decreases around $30 \%$ to $35 \%$ for skew angle $60^{\circ}$ compared to right bridge for all aspect ratio.

3) For right bridge deck slab $\left(0^{\circ}\right.$ skew $)$, maximum longitudinal sagging moments are orthogonal to abutments in central region. As the skew angle increases maximum longitudinal moments gradually shifts towards obtuse angle.

4) Torsional moment is found to be around $30 \%$ to $35 \%$ of corresponding longitudinal bending moment. In contrast to longitudinal bending and deflection torsional moment shows continuous increase in magnitude up to skew angle of $45^{\circ}$ and there after a reduction in magnitude. The peak value of torsional moment is at $45^{\circ}$ and is two times more than corresponding value for a right bridge deck.

5) For right bridge deck slabs $\left(0^{\circ}\right.$ skew), maximum torsional moments are located near all corner regions. As skew angle increases torsional moments gradually shifts towards obtuse angle.

6) The peak value of support reaction is observed at obtuse angled corner and the magnitude of reaction increases with increase in skew angle. The reactions at the obtuse angled end of slab support are larger than other end, the increase in value over average value ranging from 0 to $50 \%$ for skew angle of 15 to $45^{\circ}$. It increases around 80 $\%$, when it reaches $60^{\circ}$ compared to right bridge.

7) The advantage of providing edge beam is reflected in the reduction of the maximum torsional, maximum 
longitudinal sagging moment and maximum deflection. deflection decreases around $40 \%$ to $60 \%$ for skew angle up to $60^{\circ}$, longitudinal bending moment decreases around $60 \%$ to $70 \%$ for skew angle up to $60^{\circ}$, the reduction is even more pronounced in case of torsional moment, support reaction increases around $170 \%$ when it reaches $45^{\circ}$ and then decreases by $14 \%$ for $60^{\circ}$ skew angle compared to right bridge without edge beam for all aspect ratio.

\section{REFERENCES}

[1] C. Menassa; M. Mabsout; K. Tarhini; and G. Frederick, Influence of Skew Angle on Reinforced Concrete Slab Bridges, Journal of Bridge Engineering, Vol. 12, No. 2, March 1, 2007. (OASCE, pp 205-214.

[2] Ibrahim S. I. Harba, Effect of Skew Angle on Behaviour of Simply Supported R. C. T-Beam Bridge Decks, ARPN Journal of Engineering and Applied Sciences vol. 6, no. 8, august 2011, pp 1-14.

[3] Patrick Théoret; Bruno Massicotte; and David Conciatori, Analysis and Design of Straight and Skewed Slab Bridges, Journal of Bridge Engineering, Vol. 17, No. 2, March 1, 2012. (CASCE, pp289-301.

[4] Gholamreza Nouri, Ph.D.1; and Zahed Ahmadi, M.Sc.2, Influence of Skew Angle on Continuous Composite Girder Bridge, Journal of Bridge Engineering, Vol. 17, No. 4, July 1, 2012. CASCE, pp $617-623$.

\section{CODES}

1. IRC 6:2000 "Standard Specifications and Code of Practice for Road Bridges, Section-II Loads and Stresses", Indian Road Congress, New Delhi.

2. IRC 21:2000 "Standard Specifications and Code of Practice for Road Bridges, Section-III Cement Concrete (Plain and Reinforced)", Indian Road Congress, New Delhi. 